УДК 553:330.15:332.1

ГОРНОДОБЫВАЮЩАЯ ПРОМЫШЛЕННОСТЬ АРКТИЧЕСКОЙ ЗОНЫ ДАЛЬНЕГО ВОСТОКА: ПРОБЛЕМЫ И ПЕРСПЕКТИВЫ РАЗВИТИЯ

\author{
Шведов В.Г., Ткаченко Г.Г., Ушаков Е.А., Чурзина А.А. \\ ФГБУН «Тихоокеанский институт географии ДВО РАН», Владивосток, e-mail: i-svg@yandex.ru
}

\begin{abstract}
Статья посвящена обзору горнодобывающей промышленности Арктической зоны Дальнего Востока. Рассмотрена специфика размещения и состава сырьевого потенциала отрасли в данном регионе, дано объяснение её сложившейся специализации. Отдалённость и сложные природные, в том числе горно-геологические, условия предопределили избирательный характер добычи полезных ископаемых. В их числе одну группу образуют особо важные для жизнеобеспечения арктического региона углеводороды; другая группа представлена стратегическими видами минерального сырья, которые пользуются повышенным спросом в гражданском и военном производстве. По каждому виду рассмотренных полезных ископаемых определены особенности современного состояния и перспектив его разработки. Отмечено, что целесообразность добычи нефти и газа на шельфе Арктической зоны Дальнего Востока требует дополнительного изучения, и главным энергоносителем региона на ближайшую перспективу останется каменный уголь. На данной территории имеется один из мировых центров добычи алмазов, крупные природные запасы которого служат залогом его перспективности. Рассматриваемая территория является одним из важнейших производителей золота в России. Но его основные месторождения близки к истощению. В этой связи золотодобывающим компаниям целесообразно внедрять технологии по извлечению из руд серебра и платиноидов. Хорошую перспективу имеет восстановление добычи олова. При этом внимания заслуживают отвалы ранее отработанных месторождений. Согласно взятым пробам, содержание металла в некоторых из них выше, чем в природных рудах. Особое значение имеет нахождение в Арктической зоне Дальнего Востока крупнейших запасов редкоземельных и редких металлов. Эти материалы пользуются повышенным рыночным спросом, и их добыча представляется важным стимулом для дальнейшего развития горнодобывающей промышленности региона.
\end{abstract}

Ключевые слова: Арктика, Дальний Восток, горнодобывающая промышленность, состояние, перспективы

\title{
MINING INDUSTY OF THE ARCTIC ZONE OF THE FAR EAST: PROBLEMS AND PROSPECTS FOR DEVELOPMENT
}

\author{
Shvedov V.G., Tkachenko G.G., Ushakov E.A., Churzina A.A. \\ Pacific Geographical Institute of Far Eastern Branch of the Russian Academy of Science, \\ Vladivistok,e-mail: i-svg@yandex.ru
}

\begin{abstract}
The article is devoted to an overview of the mining industry in the Arctic zone of the Far East. The features of the location and composition of the raw material potential of the industry in this region are considered, an explanation of its current specialization is given. The remoteness and complex natural, including mining and geological, conditions have led to the selective nature of production. Among them, one group is made up of hydrocarbons, which are especially important for the life support of the Arctic region; Another group is represented by strategic types of mineral raw materials that are in demand in civilian and military production. For each type of considered minerals, the features of the current state of their development and the prospects for its development are determined. It was noted that the possibility of oil and gas production on the shelf of the Arctic zone of the Far East requires additional research, and coal in the near future will remain the main energy source for the region. One of the world's centers for diamond mining is located on this territory, and their large reserves are a guarantee of the prospects for this industry. The territory in question is one of the most important gold producers in Russia. But its main deposits are close to depletion. In this regard, it is advisable for gold mining companies to introduce technologies for extracting silver and platinoids from ores. The recovery of tin mining has good prospects. At the same time, attention should be paid to the dumps of previously worked out deposits. According to the samples taken, the metal content in some of them is higher than in natural ores. Of particular importance is the presence of the largest reserves of rare earth elements and rare metals in the Arctic zone of the Far East. These materials are in high demand in the market. and their extraction is an important incentive for the further development of the mining industry in the region.
\end{abstract}

Keywords: Arctic, Far East, mining industry, condition, prospects

Арктическую зону Дальнего Востока (АЗДВ) образуют 13 полярных улусов Республики Саха (Якутия) и Чукотский АО. Её минерально-сырьевой потенциал в основном был открыт, изучен и активно использовался в советский период. Постсоветские экономические реформы оказали на этот процесс деструктивное воздействие. Но мониторинг занятости населения и формирования валового регионального продукта, а также отчёты о финансовой деятельности предприятий указывают, что в настоящее время в экономике АЗДВ фактически сложилось состояние моноспециализации на добыче полезных ископаемых [1]. По последним данным, эта отрасль даёт $99 \%$ стоимости промышленной продукции данной территории и обеспечивает занятость более чем половины её трудоспособного населения [2;3].

Очевидно, что сложившаяся ситуация результат рыночной саморегуляции эко- 
номики региона. С позиций комплексной организации производства её, безусловно, нельзя считать удовлетворительной. Но, с другой стороны, она «естественным образом» определила стержневое значение горнодобывающей промышленности для региона. И поскольку сложности переходного периода ещё не исчерпаны, такое положение дел, скорее всего, сохранится в ближайшем будущем. Это обуславливает необходимость рассмотрения состояния данной отрасли в АЗДВ, анализ её проблем и перспектив развития.

Проблемам состояния и освоения минерально-сырьевой базы арктических территорий, а также развитию здесь горнодобывающей промышленности и ранее уделялось достаточно много внимания [4 и др.]. В последнее время интерес как к Арктическому региону в целом, так и к его ресурсному, и в частности минерально-сырьевому, потенциалу получил новый импульс в связи с быстро меняющейся геополитической обстановкой в мире [5]. Круг связанных с Арктическим регионом проблем очень широк. Неоднородность и его пространственное положение объективно заставляют уделять большее внимание западному сектору, который более приближен к европейской части Российской Федерации, где сосредоточен её основной населенческо-производственный потенциал. При этом восточный сектор Арктики оказывается несколько «в тени». В этой связи одной из причин особого интереса к АЗДВ, на наш взгляд, является актуальная для неё проблема освоения минеральных ресурсов, развития горнодобывающей промышленности. От её решения зависит перспектива самодостаточности, большей устойчивости развития этого региона, общего усиления позиций страны на её северо-восточном фланге.

Цель данного исследования состоит в проведении обзора состояния горнодобывающей промышленности Арктической зоны Дальнего Востока и формирования представления о специализации данной отрасли в регионе с целью выявления особенностей в условиях разработки основных видов минерального сырья и перспектив их добычи на ближайшее будущее.

\section{Материалы и методы исследования}

Основой написания данной статьи послужили следующие материалы: выборочные статистические данные, доступные сведения из отчётов горнодобывающих компаний, экспертные заключения по рынкам минерального сырья. При написании использованы следующие методы: камеральная обработка собранных материалов, расчётный, сравнительный, территориального и отраслевого анализа, оценочно-прогнозный.

\section{Результаты исследования и их обсуждение}

Разнообразие минерального сырья АЗДВ по преимуществу потенциальная категория: хотя в настоящее время здесь разведано боле 1,1 тыс. месторождений, среди них преобладают мелкие, эксплуатация которых экономически нецелесообразна. Разведанные крупные залежи немногочисленны и представляют собой технологически сложные для освоения объекты, поскольку наиболее доступные месторождения были исчерпаны ранее. Добычу полезных ископаемых в АЗДВ приходится вести в экстремальных горно-геологических и климатических условиях. Это является причиной высокой энерго- и теплоёмкости производства при состоянии децентрализации, относительной маломощности и высокой стоимости соответствующих видов обеспечения. Имеются и иные осложняющие производство факторы.

Большинство месторождений расположено в удалённой и труднодоступной местности, при том что транспортная сеть региона развита слабо, а её речной и сухопутный сегменты функционируют сезонно. Кроме того, действующие в горнодобывающей отрасли АЗДВ оборудование и агрегаты в постсоветское время обновлялись недостаточно, в значительной мере устарев физически и морально, при этом собственная материально-техническая и ремонтная база в регионе практически отсутствует. Отрицателен и тот факт, что некоторые виды работ, в первую очередь в газо- и нефтедобыче, существенно зависят от поставок импортной техники.

Климат АЗДВ оказывает ярко выраженное негативное воздействие на организм человека. Поэтому здесь сложился вахтовый метод ведения работ, который не способствует созданию квалифицированного профессионального контингента «на местах». Наконец, региональной особенностью является значительный, до 1,5 лет, разрыв между запуском производства и получением первой прибыли. Для действующих здесь предприятий это означает крупные инвестиционные вложения на начальном этапе, которые могут обернуться серьёзным кредитным обременением. 
Эти факторы обусловили характер горной добычи в АЗДВ. Она специализируется на разработке тех видов минерального сырья, которые либо жизненно необходимы для региона, либо обладают высокой рыночной ликвидностью. Первую из этих категорий образуют энергоносители, вторую - драгоценные камни и некоторые металлические руды.

Из-за холодного климата обеспечение электро- и теплоснабжения населения и производства является жизненно важной потребностью региона. Но его удалённость и труднодоступность осложняют и удорожают внешнее снабжение энергоносителями. Поэтому самообеспечение ими является для АЗДВ одним из самых актуальных вопросов.

Эта территория располагает полным набором углеводородного сырья, хотя состояние и перспективы использования его различных видов остаются дискуссионными. В первую очередь это касается нефтегазовых ресурсов, которые здесь сосредоточены по преимуществу на шельфе арктических морей и отличаются высокой теплотворностью. Но проведённые в 2002-2004 гг. разведка и пробное бурение дали скромный результат. Общий объём выявленных запасов углеводородов был тогда определён в 12,7 млрд тонн в нефтяном эквиваленте, что в 10 раз меньше достоверно известных запасов шельфа Печорского моря. При этом был выявлен его «разброс» по серии некрупных месторождений. Их примером на шельфе Чукотского моря стали Верхне-Эчинское- 1,5 млн т нефти и 6,9 млрд м ${ }^{3}$ газа, Верхне-Телекайское 2,8 млн т нефти и 2,2 млрд м ${ }^{3}$ газа, Угловое и Ольховское - примерно по 2,5 млн т нефти. Минимальный уровень рентабельности разработки, который равен 10 млн т нефти и 16 млрд м ${ }^{3}$ газа, был определён лишь для Западно-Анабарского шельфового участка моря Лаптевых.

По итогам проведённых работ, и учитывая перспективу создания производственной инфраструктуры «с нуля», заинтересованные компании признали развитие нефтегазового производства в АЗДВ нецелесообразным. Его единственным действующим предприятием являлось ЗападноОзёрское газовое месторождение, имеющее хоть и важное, но локальное значение. При относительно небольших (4,4 млрд м $\left.{ }^{3}\right)$ запасах газа оно расположено на суше в 100 км от города Анадырь и с 2006 г. выполняет основные функции по его энергетическому и тепловому снабжению.
Новое обследование шельфа АЗДВ 2017-2019 гг. изменило представление о его потенциале. По данным повторной разведки, перспективные ресурсы Западно-Анабарского участка составили 266 млн т нефти и около $500 \mathrm{~m}^{3}$ газа. Была произведена оценка Центрально-Оленёкского и Восточно-Анабарского участков, суммарные запасы которых определены в 4-5 млрд тонн углеводородов в нефтяном эквиваленте.

Такая перемена в оценке нефтегазовых запасов АЗДВ, безусловно, позитивна. Но она не снимает некоторых проблем. Так, необходима проверка последних оценок объёмов углеводородного сырья в регионе на достоверность, поскольку они контрастируют с полученными ранее оценками. Не изучены до конца и горногеологические условия разработки здешних потенциальных месторождений [6]. Нельзя не учитывать отсутствие специализированной производственной и транспортной инфраструктуры в местах перспективной газои нефтедобычи, при том что их создание потребует огромных средств. К примеру, расчётная стоимость запуска в эксплуатацию Западно-Анабарского участка составит 364 млрд руб. Это ставит под вопрос его конкурентоспособность с действующим и обустроенным нефтегазовым комплексом Западной Арктики.

В этой связи более ясны перспективы другого энергоносителя АЗДВ - каменного угля. Его основным источником является Беринговский бассейн в Чукотском АО. Доразведка 2017 г. позволила оценить его запасы в 4-4,5 млрд т, сосредоточенных в серии крупных залежей (Фандюшкинские поля). Их примером служит месторождение Амаам с разведанным объёмом более 500 млн т. Кроме того, Беринговский бассейн расположен близ одноимённого посёлка - рейдового порта Северного морского пути.

В 2019 г. объём добычи в Беринговском бассейне составил 382,2 тыс. т, из которых 200 тыс. экспортированы в Китай, а остальной объем закрыл потребности Чукотского $\mathrm{AO}$ в твёрдом топливе. Дальнейшее расширение производства позволит выйти к 2025 г. на годовую добычу 5 млн т. Немаловажно, что стоимость технологической модернизации инфраструктурного обеспечения угледобычи в Беринговском бассейне оценена в 1,3 млрд руб.; то есть - в стоимостном отношении выгодно отличается от несоизмеримо больших затрат на реализацию региональных нефтегазовых проектов. 
Другой крупный источник добычи каменного угля в АЗДВ - Зырянский разрез в Верхнеколымском улусе Республики Саха (Якутия). Его запасы в текущем столетии прошли переоценку с 2,6 [Расчёт по: 7] до 5 млрд т. Здешний уголь отличается с высокой долей антрацитового содержания. Его добыча осуществляется открытым способом, достигнув в 2011 г. 243 тыс. т, после чего к настоящему времени снизилась до 160 тыс. т.

Сокращение выработки зыряновского угля объясняется сложностью его доставки потребителю. На мелкосидящих судах он перевозится к устью Колымы, и далее морскими сухогрузами - в Певек, на специализированный причал для его приёма. Этот маршрут удорожается несколькими перевалками груза, осложняется сезонной функциональностью и зависимостью от текущего состояния русла Колымы. Таким образом, Зырянский бассейн в смысле рентабельности уступает Беринговскому. Однако правительство Республики Саха (Якутии) рассматривает его как один из ключевых социально-экономических объектов освоения республиканской Арктической зоны и оказывает ему утверждённую республиканской «Программой социально-экономического развития» поддержку. Благодаря этому уголь добывается здесь в рамках госзаказа с гарантией закупки его нереализованного на рынке остатка. Кроме того, ведётся согласование вопросов по установлению сквозного тарифа углеперевозки от места добычи до конечного пункта в Певеке.

Изложенное позволяет прогнозировать, что до прояснения ситуации с перспективами нефтегазового сектора, основу собственного энергобаланса АЗДВ будет составлять каменный уголь.

В группу неэнергетических минеральных ресурсов АЗДВ включены достаточно разнородные по своей природе полезные ископаемые.

В Анабарском улусе Республики Саха находится месторождение алмазов Эбелях с разведанными запасами 20 млн карат [8]. Полезный объём всего Эбеляхского комплекса с серией «дочерних» месторождений оценён в 92 млн карат [9]. Это позволяет рассматривать его как крупнейшее разведанное сосредоточение алмазов в России $(64,2 \%$ национальных запасов) и одно из крупнейших в мире.

При вводе в эксплуатацию месторождения Эбелях в 2014 г. было добыто 2 млн карат. Максимальный объём был достигнут в 2018 г. - 5,4 млн карат, затем к 2020 г. выработка снизилась до 2,9 млн. Причиной сокращения производства стало падение цен на алмазы, достигшее к настоящему времени $24 \%$ от пикового уровня 2013 г. Его вызвало совпадение обострения политической ситуации в алмазодобывающих странах Африки с переменой предпочтений в моде на украшения. Но текущее положение дел вызывает минимальную обеспокоенность, поскольку мировой рынок алмазов традиционно проходит циклы колебания цен в 7-15 лет, и в ближайшие годы ожидается их подъём. Вдобавок нереализованные камни гарантированно скупаются Гохраном, что обеспечивает бесперебойность алмазодобычи в АЗДВ.

Что касается металлических руд, то регион долгое время специализировался на добыче золота и олова. Из них главная позиция по производимой стоимости, и в настоящее время - по функциональной устойчивости, принадлежит золоту.

На АЗДВ в 2019 г. пришлось 7,8\% общероссийского производства этого благородного металла. Столь значимый показатель во многом обусловлен относительной стабильностью цен на золото. После некоторого снижения в 2010-2016 гг. они вновь показывают положительную динамику, что стимулирует его добычу в АЗДВ. В настоящее время промышленная разработка золота ведётся на Чукотке, главным образом на месторождениях Двойное, Майское (Чаунский район) и Купол (Анадырский район). В 2014-2016 гг. они давали в сумме от 21 до 24 т золота. Пиковый объём 32,1 т - достигнут в 2015 г. К 2019 г. он сократился до 20,5 т из-за уменьшения производительности месторождения Купол, на которое приходится половина региональной золотодобычи.

Это сигнализирует о том, что текущая, в целом благоприятная, ситуация с добычей золота в АЗДВ вскоре может претерпеть негативные перемены. Согласно прогнозам, «лёгкие» эксплуатационные участки на Чукотке будут исчерпаны через 3-4 года, и придётся работать с технологически сложными слоями и труднообогатимыми породами. Это поставит добывающие предприятия на грань рентабельности. Данное положение усугублено тем, что большинство из иных разведанных в АЗДВ месторождений золота невелико по размерам: в Чукотском округе - Кекура (62,1 т), Клён $(18$ т), в Республике Саха - Тарын-Юрях (2,5 т), Аччигый (451 кг). Столь малые объ- 
ёмы запасов ставят под вопрос рентабельность их освоения.

Исключением является месторождение Кучюс (Верхоянский район Республики Саха) с запасами 230 т золота. Но оно находится в труднодоступной, изолированной от путей сообщения местности. Работы по созданию его первичного инфраструктурного обеспечения оценены в 5,5 млрд руб. (в ценах до 2014 г.), что сдерживает интерес к его освоению. Это продемонстрировал в 2013 г. провал аукционных торгов на право разработки Кучюса; после них активность инвесторов к этому объекту практически пока не проявляется.

Что касается олова, то в Советском Союзе АЗДВ являлся его важнейшим производителем. Однако постсоветские реформы привели к полному обвалу этого производства. Были законсервированы или закрыты разрабатывавшиеся в Усть-Янском улусе Республики Саха месторождения Депутатское (разведанные запасы - 255 тыс. т), Тирехтях (68,9 тыс. т), Чурпунньа (11 тыс. т), а в Чукотском АО - Ильтутин (604,7 тыс. т). Не освоено крупнейшее в России и четвёртое в мире по объёму запасов (350 тыс. т) месторождение Пыркакай на Чукотке. При этом оловянные руды АЗДВ имеют высокое полезное содержание $\left(0,23-1,15\right.$ г/M $\left.\mathrm{M}^{3}\right)$ и относятся к категории легкообогатимых.

Такая ситуация объяснима в основном затяжным падением цен на олово. Начавшись в конце XX в., оно к 2015 г. «обвалило» стоимость этого металла с 63,6 до 13,6 тыс. долларов за тонну. С одной стороны, это вызвано перепроизводством: к 2019 г. объём нереализованных запасов олова составил в мире 300 тыс. т [10]. С другой - сложилась тенденция сокращения спроса на него в традиционных областях применения: тароупаковке, электротехнике, химической промышленности. Очевидно, что это явление имеет долгосрочный характер: после краткого подъёма в 2017 г. до 21 тыс. долларов за тонну цена олова к началу 2020 г. снова сократилась, потеряв до $30 \%$ обновлённого было значения. В этих условиях добывающие компании, посчитав оловодобычу в АЗДВ убыточной, свернули её.

Таким образом, добыча металлических руд в регионе в нынешнем её виде - проблемная отрасль, лишившаяся части производственного сектора и приближающаяся к утрате рентабельности. Это положение нельзя считать приемлемым. Добыча драгоценных металлов - стратегический государственный вопрос. Что касается олова, то в России спрос на него стабилен, при том что от 85 до $90 \%$ его потребляемого в стране объёма закупается за рубежом. Нельзя не учитывать и тот факт, что основные оловопроизводящие страны - Индонезия, Перу, Бразилия, сообщили о скором исчерпании ресурсов своих легкодоступных месторождений. Иными словами, олово АЗДВ представляет собой огромный резерв для импортозамещения, а ситуация с этим металлом на мировом рынке вскоре может измениться. Эти факты говорят о необходимости сохранения производства по добыче металлических руд на АЗДВ и поиске путей формирования её экономической устойчивости.

Для решения этой задачи в регионе есть потенциальные резервы. Одним из них является геологическая доразведка территории с помощью современных изыскательских технологий. Соответствующее изучение АЗДВ велось в основном в 3070 годы XX в., когда методы обнаружения и оценки полезных ископаемых были основаны лишь на самых очевидных показателях. В результате коэффициент плотности обнаруженных месторождений здесь равен 1,18 на 1 тыс. км², тогда как в среднем по России он составляет 2,2 [11]. То есть в АЗДВ есть вероятность обнаружения и новых источников минерального сырья, и переоценки в сторону укрупнения тех из них, которые уже известны. Этот подход позволит создать ситуацию, когда сложность разработки полезных ископаемых компенсируется количеством их добычи.

Другая составляющая «резервного фонда» минерального потенциала АЗДВ в буквальном смысле лежит на земной поверхности. Это отвалы действующих и отработанных предприятий. Размер их объёма точно неизвестен, но заведомо составляет несколько миллионов тонн. Применявшиеся в прошлом веке методы извлечения полезного содержания из руд не отличались полнотой. По этой причине скопившиеся в регионе отвалы представляют собой настоящие техногенные месторождения, часть из которых по качеству сопоставима с естественными. Кроме того, они доступны для разработки открытым способом, что существенно удешевляет производственный процесс.

Ранее действовавшие в АЗДВ золотодобывающие предприятия были узко специализированы на извлечении из руды именно этого металла. Впоследствии ими из породы в качестве попутного продукта стало извлекаться серебро. Ежегодный объём его 
добычи колеблется в диапазоне 130-160 т, что указывает на крупные запасы, которые используются в неполной мере.

Представляется, что золотодобывающим предприятиям целесообразно рассмотреть методы повышения извлекаемости серебра из руд. Не менее перспективным представляется изучение отвалов этого производства на предмет промышленного содержания серебра и, как показали пробы отходов месторождения Песчанка, платиноидов. В случае получения положительных результатов его проведения, база и номенклатура производства драгоценных металлов в АЗДВ могут быть значительно расширены.

Перспективы использования отвалов оловодобычи более очевидны, поскольку некоторые из них уже исследованы целевым образом. Так, изучение отходов заброшенного в 1998 г. месторождения Валькумей (близ Певека) показало в среднем $0,5 \%$ их полезного содержания [Расчёт по: 12]. При этом разработка отвалов оловодобычи считается рентабельной при показателе $0,14 \%$. Расчёт содержания олова в отвалах оставленного в 2008 г. месторождения Чурпунньа дал результат в 682 т «чистого» металла. Эти данные позволяют рассматривать накопившиеся более чем за полвека в АЗДВ отходы оловодобычи как объекты вторичного использования и значительного удешевления его производства [13].

Наконец, перспективы горнодобывающей промышленности АЗДВ могут быть усилены за счёт расширения перечня видов добываемого сырья. Но при этом следует иметь в виду, что специфика региона диктует избирательность в освоении новых видов полезных ископаемых. Основными критериями целесообразности их добычи здесь является сочетание повышенного спроса на рынке и относительной (по местным меркам) доступности разработки. В настоящее время им соответствуют ранее не добывавшиеся в АЗДВ редкие и редкоземельные металлы. С 2012 г. их потребление в мире устойчиво растёт, приняв характер долгосрочной тенденции. Основными их потребителями являются расположенные рядом с АЗДВ Китай, Южная Корея и Япония, а сама эта территория - один из немногих регионов мира, где редкозёмы представлены широкой номенклатурой наименований и повышенным содержанием в земной коре [14].

С одной стороны, источником редких и редкоземельных металлов в АЗДВ могут стать отходы оловодобычи, где они представлены как сопутствующие компоненты. Так, отвалы месторождений Пыркакай, Титерях и Депутатское содержат промышленные запасы вольфрама, индия, висмута, молибдена, бериллия, лития, тантала, ниобия. В отработанной рудной массе месторождения Пыркакай содержание каждого из этих элементов составляет $0,02 \%$, что позволяет оценивать здесь физический объём каждого из них в среднем по 21 тыс. т «чистого» металла. Открытое в 1972 г. на Чукотке медное месторождение Песчанка, несмотря на разведанные запасы в 27 млн т руды, ранее не разрабатывалось из-за низкого содержания меди. Но с 2024 г. на его основе планируется запуск комплексного Баимского ГОКа. Это решение основано на сведениях о высоком содержании вольфрама, разведанный объём которого в Песчанке в перечёте на металл составляет 28 тыс. т. Попутным объектом разработки станет уникальное природное сочетание благородных металлов: серебра, золота, платины и палладия - 2,4 тыс. тонн металлического содержания.

Что касается редкоземельных металлов, то они представлены в АЗДВ как основные рудообразующие элементы. Из их месторождений наиболее известно Томтор в Оленёкском улусе Якутии. Его основным полезным содержанием являются ниобий и редкозёмы иттриевой и церриевой групп, содержание которых в породе составляет 5 и $12 \%$ соответственно. По этим показателям и объёму запасов руды в 150 млн т Томтор превосходит крупнейшие в мире аналоговые месторождения Китая и Бразилии [15]. На его основе в 2024 г. планируется запуск ГОКа с добычей руды открытым способом и начальной мощностью 500 тыс. т редкоземельного концентрата.

\section{Заключение}

Несмотря на имеющиеся сложности, АЗДВ по многим позициям представляет собой регион, перспективный для развития горнодобывающей промышленности. Но в непростых условиях региона эта отрасль не будет иметь должной эффективности без активной господдержки.

Определённые шаги в этом направлении предприняты. Так, Гохран тесно взаимодействует с алмазо- и золотодобывающими предприятиями, скупая их нереализованную продукцию по гарантированным ценам. С 2011 г. введена нулевая ставка налога для работающих на Дальнем Востоке 
оловодобывающих компаний. В 2020 г. принят закон о снижении налога с 8 до $4,8 \%$ на добычу редких и редкоземельных металлов при разработке как непосредственно их месторождений, так и при промышленном содержании таковых в составе многокомпонентных руд.

Однако в целом эти шаги следует признать фрагментарными и не во всём учитывающими специфику АЗДВ. К примеру, за годы обнуления налога на добычу олова его добыча на юге Дальнего Востока возросла на $6,9 \%$; но в Арктической зоне позитивных перемен в этой связи не произошло, что объяснимо разницей в природных условиях и условиях работы между двумя частями данного макрорегиона. Кроме того, государственная доля участия в проектах освоения новых месторождений в Арктике не превышает $1 / 17$ от общей суммы инвестиций, что зачастую делает их «неподъёмными» даже для объединений предпринимателей и обозначает нежелание федерального центра иметь дело с трудно осваиваемыми ресурсами.

Эти факты указывают на то, что конкретизированное представление о решении некоторых экономических проблем АЗДВ на государственном уровне пока не сложилось. Такое положение дел следует признать неудовлетворительным. Восточная Арктика представляет собой обширный фланг всей Арктической зоны России. Её роль в сохранении национального контроля над крупными запасами стратегического сырья, артерией Северного морского пути, в поддержании геостратегического баланса со странами HATO со стороны Западного полушария - очевидна. Но все эти функции могут быть успешно выполнены лишь достаточно сильным в экономическом отношении регионом. Отсюда следует вывод: поскольку горнодобывающая промышленность является главным «локомотивом» экономики АЗДВ и, судя по всему, останется таковым в обозримом будущем, она должна стать объектом пристального внимания со стороны государства и неформального подхода к мерам по её устойчивому развитию на самом высоком уровне.

Результаты исследований получень в рамках государственного задания Минобрнауки РФ (тема «Географические и геополитические факторы в инериионности, динамике и развитии разноранговых территориальных структур хозяйства и расселения населения Тихоокеанской России», № ААAA-A16-116110810013-5. Раздел 1).
Исследование выполнено при финансовой поддержке РФФИ в рамках научного проекта № 18-05-60103.

\section{Список литературы / References}

1. Мошков А.В. Социально-экономическая эффективность территориально-отраслевой структуры экономики субъектов Дальневосточного федерального округа Российской Федерации // Экономические проблемы регионов и отраслевых комплексов. 2019. № 2 (70). С. 124-131.

Moshkov A.V. Socio-economic efficiency of the territorial and branches structure of the economy of the subjects of the Far Eastern District of the Russian Federation // Ekonomicheskie problemy regionov i otraslevych kompleksov. 2019. № 2 (70). P. 124-131 (in Russian).

2. Ушаков Е.А. Собственные и внешнеэкономические факторы развития Арктических районов Республики Саха (Якутия) // Пространственная организация общества: теория, методология, практика: материалы Всероссийской научно-практической конференции (г. Пермь, 7-11 ноября 2018 г.). Пермь: Издательство ПГНИУ, 2018. С. 566-571.

Ushakov E.A. Own and external economic factors of the development of the Arctic regions of the Republic of Sakha (Yakutia) // Prostranstvennaya organizatsiya obshchestva: teoriya, metodologiya, praktika: materialy Vserossijskoj nauchno-prakticheskoj konferentsii (g. Perm', 7-11 noyabrya 2018 g.). Perm': Izdatel'stvo PGNIU, 2018. P. 566-571 (in Russian).

3. Чурзина А.А. Анализ развития сетей городского расселения юга Российского Дальнего Востока // Геосистемы в Северо-Восточной Азии: типы, современное состояние и перспективы развития: материалы Всероссийской научнопрактической конференции (г. Владивосток, 19-20 апреля 2018 г.). Владивосток: Издательство Тихоокеанского института географии ДВО РАН, 2018. С. 448-454.

Churzina A.A. Analysis of the development of urban settlement networks in the south of the Russian Far East// Geosistemy v Severo-Vostochnoj Azii: tipy, sovremennoe sostoyanie i perspektivy razvitiya: materialy Vserossijskoj nauchno-prakticheskoj konferentsii (g. Vladivistok, 19-20 aprelya 2018 g.). Vladivostok: Izdatel'stvo Tikhookeanskogo instituta geografii DVO RAN, 2018. Р. 448-454 (in Russian).

4. Додин Д.А., Каминский В.Д., Золоев К.К., Коротеев В.А. Стратегия освоения и изучения минерально-сырьевых ресурсов Российской Арктики и Субарктики в условиях перехода к устойчивому развитию // Литосфера. 2010. № 6. C. $3-24$.

Dodin D.A., Kaminskij V.D., Zoloev K.K., Koroteev V.A. Strategy for the developing and study of mineral resources of the Russian Arctic and Subarctic in the context of the transition to sustainable development// Litosfera. 2010. № 6. P. 3-24 (in Russian).

5. Романов М.Т., Шведов В.Г. Выделение и обоснование геополитического региона Берингия // Общественногеографическая структура и динамика современного Евразийского пространства: вызовы и возможности для России и её регионов: материалы Международной научной конференции (г. Владивосток, 14-20 сентября 2020 г.). Владивосток: Издательство Тихоокеанского института географии ДВО РАН, 2020. С. 251-259.

Romanov M.T., Shvedov V.G. Identification and substantiation of the geopolitical region of Beringia // Obshchestvenno-geograficheskaya struktura i dinamika sovremennogo Evrazijskogo prostranstva: vyzovy i vozmozhnosti dlya Rossii i ee regionov: materialy mezhdunarodoj nauchnoj konferentsii (g. Vlsdivostok, 14-20 sentyabrya 2020 g.). Vladivistok: Izdatel'stvo Tikhookeanskogo instituta geografii DVO RAN, 2020. P. 251-259 (in Russian).

6. Суслова А.А., Ступакова А.В., Коротков С.Б., Карнаухов С.М., Книппер А.А., Шелков Е.С., Баранова Д.Б., Радченко К.А., Гилаев Р.М., Степанов П.Б. Нефтегазоносные бассейны шельфа России // Геологоразведка. 2020. № 1. С. 52-64.

Suslova A.A., Stupakova A.B., Korotkov S.B., Karnaukhov S.M., Knipper A.A., Shelkov E.S., Baranova D.B., Rad- 
chenko K.A., Gilaev R.M., Stepanov P.B. Oil and gas basins of the Russian sea shelf // Geologorazvedka. 2020. № 1. P. 5264 (in Russian).

7. Батугина Н.С., Гаврилов В.Л., Хоютанов Е.А., Фёдоров В.И. Угольные месторождения Арктической зоны Якутии и Чукотки: состояние сырьевой базы и возможности её освоения // Наука и образование. 2014. № 4. С. 5-11.

Batugina N.S., Gavrilov V.L., Khojutanov E.A., Fedorov V.I. Coal deposits of the Arctic zone of Yakutia and Chukotka: the condition of the raw material base and the possibility of its development // Nauka i obrazovanie. 2014. № 4. P. 5-11 (in Russian).

8. Краткий отчёт независимых экспертов о запасах и ресурсах месторождений алмазов группы компаний АЛPOC. Норидж: Майкон Интернешнл Ко Лимитед, 2018. 34 с

The brief report by independent experts about reserves and resources of diamond deposits of the ALROS group of companies. Norwich: Micon International Co Limited, 2018. 34 p. (in Russian).

9. Новые месторождения АЛРОСа - возможные источники роста запасов алмазов. [Электронный ресурс]. URL: https:// www.interfax.ru/business/235642 (дата обращения: 23.01.2021).

The New deposits of the ALROS - possible sources of increase of the diamond reserves. [Electronic resource]. URL: https://www.interfax.ru/business/235642 (date of access: 23.01.2021) (in Russian).

10. Металлургический бюллетень. [Электронный реcypc]. URL: https://www.metalbulletin.ru/news/color/10149770/ (дата обращения: 16.01.2021).

The Metallurgical Bulletin. [Electronic resource]. URL: https://www.metalbulletin.ru/news/color/10149770/ (date of access: 16.01.2021) (in Russian).

11. Ткаченко Г.Г. Сочетание минеральных ресурсов зоны суша-океан в арктическом регионе российского Дальнего Востока // Геосистемы Северо-Восточной Азии: особенности их пространственно-временных структур, районирование территории и акватории: материалы Всероссийской научно-практической конференции (г. Владивосток, 20-21 апреля 2019 г.). Владивосток: Издательство Тихоокеанского института географии ДВО РАН, 2019. С. 562-568.
Tkachenko G.G. Combination of mineral resources of the land-ocean zone in the Arctic region of the Russian Far East// Geosistemy Severo-Vostochnoj Azii: osobennosti ikh prostranstvenno-vremennykh struktur, rajonirovanie territorii i akvatorii: materialy Vserossijskoj nauchno-prakticheskoj konferentsii (g. Vladivostok, 20-21 aprelya 2019 g.). Vladivostok: Izdatel'stvo Tikhookeanskogo instituta geografii DVO RAN, 2019. P. $562-568$ (in Russian)

12. Лаломов А.В., Таболич С.Э. Прогнозируемая динамика техногенных россыпей в береговой зоне моря на основе численного моделирования на примере Валькумейского месторождения // Геология рудных месторождений. 2009. T. 51. № 3. C. 239-249.

Lalomov A.V., Tabolich S.E. Predicted dynamics of technogenic placers in the coastal zone of the sea based on numerical modeling using the example of the Valkumejskoe mining field // Geologiya rudnych mestorozhdenij. 2009. Vol. 51. № 3. P. 239249 (in Russian).

13. Шац М.M. Инженерно-геологические аспекты освоения месторождений олова Яно-Индигирской провинции. [Электронный ресурc]. URL: https://www.geoinfo. ru/product/shac-mark-mihajlovich/inzhenerno-geologicheskieaspekty-osvoeniya-mestorozhdenij-olova-yano-indigirskoj-provincii-s-v-yakutiya-41397.shtml (дата обращения: 10.01.2021).

Shats M.M. Geotechnical aspects to the mastering of tin deposits in the Yano-Indigirskaya province [Electronic resource]. URL: https://www.geoinfo.ru/product/shac-mark-mihajlovich/ inzhenerno-geologicheskie-aspekty-osvoeniya-mestorozhdenijolova-yano-indigirskoj-provincii-s-v-yakutiya-41397.shtml (date of access: 10.01.2021) (in Russian).

14. Smith M., Moore K., Kavecsanszhi D., Finch A., Kynicky J., Wall F. From mantle to critical zone: A review of large and giant sized deposits of the rare earth elements. Geoscience Frontiers. 2016. Vol. 7. No. 3. P. 315-334.

15. Григорьев В.П., Петухов Г.Е. Перспективы и проблемы освоения ниобий-редкоземельного месторождения Томтор // Экономика и управление. 2013. № 25 (304). С. 27-31.

Grigor'ev V.P., Petukhov G.E. Prospects and problems to the mastering of the niobium and rare-earth deposit Tomtor // Ekonomika i upravlenie. 2013. № 25 (304). P. $27-31$ (in Russian). 